\title{
Principais desafios do acolhimento na prática da atenção à saúde bucal: subsídios iniciais para uma crítica
}

\author{
Leonardo Carnut*; Matheus Pereira Frazão**; José Gomes de Moura Neto**; Ana Lívia Alves de Sá \\ Silva**
}

* Docente do curso de Odontologia da Universidade de Pernambuco

** Acadêmico do curso de Odontologia da Universidade de Pernambuco

Recebido em 12/06/2017. Aprovado em 08/11/2017.

\begin{abstract}
RESUMO
Este estudo teve como objetivo revisar os principais desafios enfrentados pelo acolhimento como estratégia de humanização na atenção à saúde bucal, visando compreender como a saúde bucal coletiva vem se apropriando dessa temática. Tratou-se de uma revisão narrativa cujo objeto foi o acolhimento nas práticas de saúde bucal. Utilizou-se o portal Bireme para realizar a busca com uso dos termos: 'acolhimento' e 'saúde bucal'. Artigos com resumo, disponíveis em texto completo e em idioma português foram os critérios de inclusão. Totalizou-se 19 artigos incluídos, dos quais 68,5\% estavam indexados na base LILACS. Dentre os desafios a serem enfrentados na implementação do acolhimento, o principal foi "relações tensas, devido às queixas e falta de resolubilidade do serviço e do sistema". Quanto à forma de apropriação deste tema, a aposta feita é na compreensão do acolhimento como proposta micropolítica, descaracterizando-a como uma relação de produção inserida no todo social.
\end{abstract}

Descritores: Humanização da Assistência. Acolhimento. Saúde Bucal.

\section{INTRODUÇÃO}

O processo de criação do Sistema Único de Saúde (SUS) é permeado de intensas contradições. Elas vão desde a subserviência do setor saúde à lógica de acumulação capitalista ${ }^{1}$ até a defesa da 'saúde' como um direito social no Brasil em face à ordem global situada anos 197080.
Por mais que se identifique o processo de mercantilização da saúde nas práticas cotidianas do sistema (tanto em sua forma complementar, como na assistência direta) ${ }^{2}$ é essencial reconhecer que, pelo lado dos que resistem a essa lógica, a aposta tem sido em reconfigurar o encontro entre 'usuário e profissional de saúde', na tentativa de amortizar o peso da estrutura 
social em degradar o trabalho e reduzi-lo cada vez mais a uma prática interventiva, numérica, pragmática, ou seja, despida de sua dimensão subjetiva.

É neste sentido que, para estes defensores, a Humanização em Saúde, e sua elaboração enquanto política pública apresenta certa relevância, haja vista a crença de que, pelo menos no mundo do 'trabalho em saúde', seja possível reorientar as práticas em direção a um 'cuidado, 3 nos limites do que os gestores, trabalhadores e usuários possam implementar em suas microrrelações.

Foi sob este debate que, em 2003, o Governo Federal apresentou a Política Nacional de Humanização (PNH). Ressaltou-se, naquele período, que o desafio a ser enfrentado era a 'relação de produção do trabalho em saúde' e enfatizou-se que a 'Humanização da Saúde' era uma questão complexa e essencial para consolidação do SUS. Assim, a PNH foi o marco político inicial para a implementação de uma nova 'forma de trabalhar' que visava operacionalizar os princípios da universalidade, integralidade e equidade nos encontros produzidos nos serviços ${ }^{4,5}$.

A humanização em saúde é uma estratégia de fortalecimento do SUS, que surgiu como resposta ao cenário em que o mesmo se encontrava na década de 1990. Seu objetivo era contribuir para a melhoria da qualidade da atenção e da gestão da saúde no Brasil por meio do fortalecimento da humanização como política transversal na rede, afirmando a indissociabilidade do modelo de atenção e de gestão ${ }^{4}$.

Nesta política pública, humanizar significa valorizar a subjetividade do ser humano; diz respeito a uma aposta ético-estético-política: ética, porque implica a atitude de usuários, gestores e trabalhadores de saúde comprometidos e corresponsáveis com a saúde dos sujeitos. Estética, porque exige um processo criativo e sensível de produção da saúde e proporciona subjetividades autônomas e protagonistas. Política, porque se refere à organização social e institucional das práticas de atenção e gestão na rede do SUS $^{5}$.

Esses enunciados tentam incutir no 'espaço da produção do cuidado' (espaço inter-relacional entre profissional e usuário) a pecha de que é possível o profissional realizar a luta política mudando o 'vetor' dos poderes que se cristalizam no seu microespaço de trabalho. Sob esse argumento, a criatividade e a artesania do ato de 'cuidar' (dimensão estética) assim como o respeito aos valores e o altruísmo (dimensão ética) teriam, por si só, a capacidade de realinhar o 'vetor-força' (ou seja, a força exercida pelo poder da dinâmica social capitalista sobre o trabalho dos sujeitos) em 'módulo', 'direção' e 'sentido' opostos ao processo de fetichização da mercadoria.

É importante ressaltar que esta aposta sobre humanização na qual a PNH se apoia padece de críticas, especialmente quando Bensaïd (2008) ${ }^{6}$, afirma que a política é irredutível à estética e à ética:

"A estetização da política constitui uma resposta recorrente às crises da democracia. Os entusiasmos pelo local e pelas proximidades, a busca das origens, o acúmulo ornamental e o simulacro da autenticidade revelam, de fato, a angústia contemporânea diante da incerteza da ação política. [...] [Já o] moralismo bempensante esforça-se, assim para recuperar rapidamente o que uma política desmoralizada deixa escapar. Essa secreção intensa de suores éticos é característica dos períodos de medo e impotência, em que a ação busca suas justificativas ora aquém ora além da política. Contra essas efusões, Freud observou sobriamente que uma mudança 
de atitude dos homens em relação à propriedade seria mais eficaz do que qualquer preceito ético, que nada mais tem a nos oferecer além da satisfação narcisista de podermos nos considerar melhor do que os outros." (p. 25-26).

Mesmo sob essa crítica, a aposta descrita na PNH é aquela que ganhou adesão e notoriedade no âmbito do SUS e da Saúde Coletiva. Através dela, um 'arsenal' de 'formas instrumentais' sobre o 'humanizar os serviços' foram sendo construídas traduzindo-se em métodos, diretrizes, estratégias e dispositivos, sendo o acolhimento uma delas. Portanto, o acolhimento no campo da saúde deve ser entendido, ao mesmo tempo, como diretriz ética/estética/política constitutiva dos modos de se produzir saúde assim como uma 'ferramenta tecnológica' de intervenção na qualificação da escuta, construção do vínculo, garantia do acesso com responsabilização e resolutividade nos serviços ${ }^{4,5}$.

Silva et al. $(2011)^{7}$ conceituam sua face instrumental:

"O acolhimento, enquanto uma das estratégias da PNH tem por objetivos ampliar e qualificar o acesso dos usuários, assumindo a condição de reorganizador do processo de trabalho no sentido de promover a humanização da assistência à saúde. Compreendido como trocas solidárias e comprometidas com a produção da saúde, é um dos dispositivos da PNH que influenciam diretamente alguns princípios do SUS. Salienta a necessidade de o olhar do usuário ser complementar ao dos trabalhadores (aqui entendidos como colaboradores [grifo nosso]) e do gestor, e vice-versa, transpondo a individualidade e o verticalismo." (p. 36).

Em que pese a importância dos diversos dispositivos de Humanização da Saúde e a indissociabilidade entre eles para uma prática 'humanizada' segundo os padrões dos formuladores de políticas públicas ${ }^{8}$, há uma espécie de 'cantilena' a favor do acolhimento como uma das atividades fundamentais do ato de 'humanizar'. É conspícuo como o imaginário social daqueles que trabalham na assistência ou que gerenciam os serviços de saúde referem-se ao acolhimento como tarefa precípua de quaisquer relações sociais na saúde.

Um fator que corrobora esse argumento é a gama de estudos na área da Saúde Coletiva que elegem o acolhimento como objeto de estudo ${ }^{9,10}$ além da farta produção que vem se dedicando, nem que seja tangencialmente, sobre essa questão ${ }^{11,12}$. Por esta razão, parece razoável identificar como a saúde bucal coletiva vem dialogando com essa temática e, acima de tudo, compreender a natureza dessa apropriação no que se refere aos desafios no âmbito das práticas empíricas que ocorrem nos serviços que estão registradas na literatura científica.

Assim, o presente estudo pretendeu revisar os principais desafios enfrentados pelo acolhimento como estratégia de humanização na atenção à saúde bucal visando compreender como a saúde bucal coletiva vem se apropriando dessa temática.

\section{MÉTODO}

O presente estudo se caracteriza como uma revisão narrativa conforme descrito por Rother $(2007)^{13}$ cujo objetivo foi identificar quais são os principais desafios enfrentados pelas estratégias de acolhimento na busca pela humanização da atenção à saúde bucal no SUS.

Para isso, três perguntas fundamentais guiaram a extração dos dados dos artigos incluídos nessa revisão: a) o que o texto apresenta como conceito de acolhimento? b) qual a importância que o texto discorre sobre o 
acolhimento? e c) qual(is) os desafios enfrentados na operacionalização do acolhimento na atenção à saúde bucal?

Neste sentido, a primeira etapa consistiu em um procedimento de busca sistematizada nas bases de dados que indexam estudos nessa temática. Assim, elegeu-se o portal de informação científica da Biblioteca Virtual em Saúde (Bireme), (www.bvsalud.org) como ponto de partida para coletar os dados relacionados ao tema.

Foi utilizado o cruzamento dos termos: 'acolhimento' e 'saúde bucal' presentes no título, resumo e assunto, totalizando 177 estudos identificados. Destes, apenas 42 estavam disponíveis na íntegra, dentre os quais eram 12 estudos repetidos, 7 teses, 1 monografia e, portanto, estes estudos não compuseram o escopo final por não se apresentarem em formato de artigo científico. Em adição, um artigo cuja experiência descrita estava localizada em Lisboa, Portugal, um artigo que apresentava-se na versão em inglês apenas e outro artigo que não estava disponível não foram incluídos. Ao total, obtevese 19 artigos científicos incluídos na revisão, disponíveis gratuitamente e que atingiram os critérios estabelecidos além de apresentarem resumo e estarem escritos em língua portuguesa.

\section{RESULTADOS}

Os artigos desta revisão narrativa foram coletados através do portal Bireme e apresentaram a seguinte distribuição por banco de dados de indexação (tabela 1).

A maior parte dos estudos (13) se encontram indexados na base de dados LILACS (68,5\%). A partir da identificação das bases de dados, confirmação da disponibilidade gratuita dos estudos e serem filtrados pelos critérios estabelecidos.

O primeiro estudo data de 2006, quando os pesquisadores da área da saúde bucal coletiva iniciam aproximações ao acolhimento como objeto de estudo. Após essa primeira sistematização, os estudos foram lidos na íntegra e seus achados, segundo o interesse de investigação desta revisão (conceito, importância e desafios), puderam ser identificados no quadro 1.

Tabela 1. Bases de dados do portal Bireme nas quais se encontravam os artigos incluídos na revisão narrativa sobre acolhimento e saúde bucal.

\begin{tabular}{lcc} 
Bases de dados & n & $\boldsymbol{\%}$ \\
\hline LILACS & 13 & 68,5 \\
BBO & 5 & 26,3 \\
Psicologia & 1 & 5,2 \\
\hline Total & $\mathbf{1 9}$ & $\mathbf{1 0 0 , 0}$ \\
\hline
\end{tabular}

Fonte: Pesquisa direta

Segundo o quadro 1, é possível identificar que a maior parte dos estudos (12) se utilizam de métodos qualitativos $(63,1 \%)$. Nove artigos (47,3\%) do total (19) não apresentam uma conceituação sobre acolhimento. Cinco artigos $(26,3 \%)$ não apresentaram a importância relacionada ao acolhimento que justificariam a escolha da temática como objeto estudo. Outros cinco artigos (26,3\%) não apresentaram os desafios relacionados a implantação das práticas de acolhimento na atenção à saúde bucal.

\section{DISCUSSÃO}

De acordo com os achados dessa revisão foi possível perceber que há uma variada forma de apropriação da temática do acolhimento pela produção científica em saúde bucal coletiva e varia desde a mera citação do termo sem sequer descrevê-lo ou conceituá-lo, passando pelo uso inapropriado e/ou operacionalização biomedicalizada, até o uso apropriado do termo e sua identificação mais precisa em práticas e relatos de experiências nos serviços. 


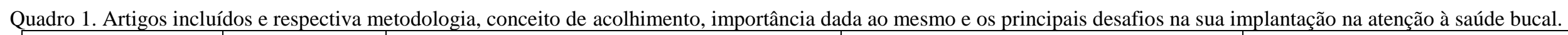

\begin{tabular}{|c|c|c|c|c|}
\hline Autores - Ano & Metodologia & Conceito de Acolhimento & Importância dada ao Acolhimento & $\begin{array}{c}\text { Principais desafios na implantação } \\
\text { do Acolhimento }\end{array}$ \\
\hline $\begin{array}{l}\text { Moimaz et al. - } \\
2017\end{array}$ & Quantitativa & $\begin{array}{l}\text { Compreende desde a entrada do usuário no } \\
\text { sistema de saúde e a responsabilização } \\
\text { integral de suas necessidades até a atenção } \\
\text { resolutiva de todos os seus problemas }\end{array}$ & $\begin{array}{l}\text { Pode então provocar a reorganização } \\
\text { do serviço ao atender positivamente } \\
\text { os entraves em saúde dos usuários. } \\
\text { É uma estratégia que potencializa o } \\
\text { acesso e permite priorizar grupos de } \\
\text { risco, social e epidemiológico. } \\
\text { Em saúde bucal se apresenta como um } \\
\text { dispositivo capaz de nortear a } \\
\text { organização e o planejamento das } \\
\text { atividades desenvolvidas no SUS, de } \\
\text { forma mais eficiente e produtiva, } \\
\text { transformando-se em um importante } \\
\text { instrumento de gestão }\end{array}$ & $\begin{array}{l}\text { A equipe profissional e os gestores } \\
\text { locais dos serviços ainda têm grandes } \\
\text { dificuldades em compreender o que } \\
\text { realmente significa o acolhimento e } \\
\text { quais são as etapas e estratégias que } \\
\text { norteiam esse processo. } \\
\text { Atendimento prestado pela equipe de } \\
\text { saúde bucal e a disponibilidade de seus } \\
\text { membros para dialogar sobre dúvidas, } \\
\text { preocupações e problemas de saúde } \\
\text { bucal foram os fatores que mais } \\
\text { impactaram na sua qualificação }\end{array}$ \\
\hline $\begin{array}{l}\text { Costa et al. - } \\
2016\end{array}$ & $\begin{array}{l}\text { Protocolo de } \\
\text { atendimento }\end{array}$ & $\begin{array}{l}\text { Não apresenta um conceito sobre } \\
\text { acolhimento. }\end{array}$ & $\begin{array}{l}\text { Não apresenta a importância do } \\
\text { acolhimento. }\end{array}$ & $\begin{array}{l}\text { Não apresenta desafios relacionados ao } \\
\text { acolhimento. }\end{array}$ \\
\hline $\begin{array}{l}\text { Bordin et al. - } \\
2016\end{array}$ & $\begin{array}{l}\text { Estudo } \\
\text { transversal, } \\
\text { de caráter } \\
\text { qualitativo }\end{array}$ & $\begin{array}{l}\text { Não apresenta um conceito sobre } \\
\text { acolhimento. }\end{array}$ & $\begin{array}{l}\text { Ressalta que a qualidade dos serviços } \\
\text { de saúde, na percepção de usuários, } \\
\text { está intimamente ao acolhimento e a } \\
\text { comunicação com os profissionais. }\end{array}$ & $\begin{array}{l}\text { Apesar de todos os avanços impetrados } \\
\text { no acolhimento em saúde, esses anseios } \\
\text { continuam permeando a fala de } \\
\text { usuários, conforme excertos de } \\
\text { sujeitos: } \\
\text { "Ter atendimento noturno para as } \\
\text { pessoas que trabalham". "Demora pra } \\
\text { ser atendido, ter que ir muito cedo" }\end{array}$ \\
\hline $\begin{array}{l}\text { Casotti, Gabriel - } \\
2016\end{array}$ & $\begin{array}{l}\text { Quantitativo, } \\
\text { descritivo e } \\
\text { analítico }\end{array}$ & $\begin{array}{l}\text { Constitui-se numa ação que deve ocorrer } \\
\text { em todos os momentos e locais do serviço, } \\
\text { não se limitando ao recebimento da } \\
\text { demanda espontânea para identificação de } \\
\text { riscos ou urgências, mas, sim, pautar-se } \\
\text { pelo desenvolvimento de maneiras }\end{array}$ & $\begin{array}{l}\text { Dados sugerem a necessidade de } \\
\text { maior discussão } \\
\text { operacionalização do acolhimento, } \\
\text { pois só a metade das equipes } \\
\text { apresentou documento orientador da } \\
\text { acão. }\end{array}$ & $\begin{array}{l}\text { Ao serem perguntados sobre a } \\
\text { existência do acolhimento à demanda } \\
\text { espontânea para a saúde bucal, } 80,6 \% \\
\text { afirmam realizá-lo. O percentual mais } \\
\text { baixo está localizado na AP } 3.1 \text {, com } \\
64,1 \% \text {. Enquanto a utilizacão de }\end{array}$ \\
\hline
\end{tabular}




\begin{tabular}{|c|c|c|c|c|}
\hline & & $\begin{array}{l}\text { adequadas de receber os distintos modos } \\
\text { com que a população busca auxílio nos } \\
\text { serviços de saúde, sempre respeitando o } \\
\text { momento existencial de cada usuário, } \\
\text { recebendo-o bem, com disponibilidade } \\
\text { para escutá-lo e buscando formas de } \\
\text { compreendê-lo e solidarizar-se com ele. }\end{array}$ & & $\begin{array}{l}\text { protocolo para o acolhimento é relatada } \\
\text { por } 75,3 \% \text { do total de equipes, a AP } 3.1 \\
\text { acumula, junto com o menor percentual } \\
\text { de realização da atividade, também o } \\
\text { menor percentual de uso de um } \\
\text { protocolo }(56,4 \%) \text {. }\end{array}$ \\
\hline $\begin{array}{l}\text { Rodrigues et al. - } \\
2015\end{array}$ & Qualitativo & $\begin{array}{l}\text { Acolhimento não é necessariamente uma } \\
\text { atividade em si, mas conteúdo de toda a } \\
\text { atividade assistencial, consistindo na busca } \\
\text { de reconhecimento das necessidades de } \\
\text { saúde dos usuários e das formas possíveis } \\
\text { de satisfazê-las, isto é, resultando em } \\
\text { encaminhamentos, deslocamentos e e } \\
\text { trânsitos pela rede assistencial. }\end{array}$ & $\begin{array}{l}\text { Possui um papel fundamental na rede } \\
\text { de conversações que constitui um } \\
\text { serviço de saúde, devendo ocupar } \\
\text { todas as etapas. Assim desempenha o } \\
\text { papel de receber e interligar uma } \\
\text { conversa à outra, conectando os } \\
\text { diferentes espaços, devendo ocorrer } \\
\text { em qualquer encontro entre } \\
\text { trabalhador-usuário, desde a porta de } \\
\text { entrada até a saída do serviço de saúde }\end{array}$ & $\begin{array}{l}\text { O discurso dos estudantes deixa } \\
\text { transparecer a falta de compreensão do } \\
\text { que seja acolhimento em seu sentido } \\
\text { ampliado, ao referir a inexistência de } \\
\text { funcionários para orientar os usuários } \\
\text { em relação à dinâmica de } \\
\text { funcionamento das clínicas e de } \\
\text { realização dos procedimentos } \\
\text { odontológicos } \\
\text { Os usuários, com relação ao } \\
\text { acolhimento relataram: } \\
\text { "Não tenho o que reclamar, o } \\
\text { atendimento é muito bom. A atendente } \\
\text { apresenta muita simpatia, sabe } \\
\text { resolver as coisas" } \\
\text { "Achei excelente, fui bem recebido. } \\
\text { Desde a recepcionista até o } \\
\text { atendimento com o aluno". } \\
\text { Percebeu-se nesse estudo a necessidade } \\
\text { de ampliação da escuta, com } \\
\text { implantação efetiva do acolhimento. }\end{array}$ \\
\hline $\begin{array}{l}\text { Sanchez et al. - } \\
2015\end{array}$ & $\begin{array}{l}\text { Revisão } \\
\text { Integrativa }\end{array}$ & $\begin{array}{l}\text { Não apresenta um conceito sobre } \\
\text { acolhimento. }\end{array}$ & $\begin{array}{l}\text { A ideia de integralidade } \text { esteve } \\
\text { fortemente ligada aos } \text { seus } \\
\text { dispositivos (acolhimento, vínculo, } \\
\text { responsabilização) }\end{array}$ & $\begin{array}{l}\text { Repensar os vínculos empregatícios, } \\
\text { muitas vezes precários e levando a uma } \\
\text { rotatividade dos trabalhadores, pois o } \\
\text { resultado pode ser o comprometimento } \\
\text { do acolhimento }\end{array}$ \\
\hline
\end{tabular}


Principais desafios do acolhimento na prática da atenção à saúde bucal: subsídios iniciais para uma crítica

\begin{tabular}{|c|c|c|c|c|}
\hline $\begin{array}{l}\text { Lawrence } \text { et al. - } \\
2014\end{array}$ & $\begin{array}{l}\text { Quantitativo } \\
\text { Transversal }\end{array}$ & $\begin{array}{l}\text { O acolhimento é uma ferramenta da } \\
\text { Política Nacional de Humanização }\end{array}$ & $\begin{array}{l}\text { Ressalta a importância do tema } \\
\text { acolhimento em capacitações para } \\
\text { cirurgiões-dentistas. }\end{array}$ & $\begin{array}{l}\text { Cirurgiões-dentistas com maior idade e } \\
\text { mais tempo de formados foram aqueles } \\
\text { que, em maior percentual, não } \\
\text { souberam avaliar o acolhimento das } \\
\text { suas unidades de saúde. } \\
\text { Dificuldades no manejo do tratamento } \\
\text { odontológico de pacientes especiais } \\
\text { compromete o acolhimento das } \\
\text { demandas odontológicas dessa } \\
\text { população. }\end{array}$ \\
\hline $\begin{array}{l}\text { Neves, Ely, } \\
\text { Pretto - } 2013\end{array}$ & Qualitativa & $\begin{array}{l}\text { O acolhimento pressupõe um serviço de } \\
\text { saúde organizado de forma usuário- } \\
\text { centrada, garantido por uma equipe } \\
\text { multiprofissional nos atos de receber, } \\
\text { escutar, orientar, atender, encaminhar e } \\
\text { acompanhar os indivíduos } \\
\text { Um espaço de encontro entre trabalhador e } \\
\text { usuário, que se abre para um momento de } \\
\text { escuta dos problemas, troca de } \\
\text { informações, mútuo reconhecimento de } \\
\text { direitos e deveres e, também, como um } \\
\text { processo de tomada de decisões. A acolhida } \\
\text { prevê a oferta de serviços às carências } \\
\text { demandadas, bem como } \\
\text { responsabilização integral pelos problemas } \\
\text { de saúde de uma coletividade, por meio das } \\
\text { tecnologias disponíveis. } \\
\text { Acolhimento como objeto de práticas } \\
\text { implica relacioná-lo aos modelos de } \\
\text { atenção à saúde, que investem na qualidade } \\
\text { dos serviços, tendo a responsabilização } \\
\text { como produto e produtor de dispositivos }\end{array}$ & $\begin{array}{l}\text { Considera o acolhimento como uma } \\
\text { importante ferramenta de acesso aos } \\
\text { serviços de saúde e, também, como } \\
\text { uma proposta de mudança do } \\
\text { processo de trabalho em saúde }\end{array}$ & $\begin{array}{l}\text { Acolhimento, enquanto estratégia de } \\
\text { acesso para o serviço de saúde bucal, } \\
\text { significou uma mudança na forma de } \\
\text { atendimento. } \\
\text { Ainda existem algumas dificuldades } \\
\text { em garantir o acesso universal, mesmo } \\
\text { após a implantação do acolhimento, o } \\
\text { que reitera o ideário de que quanto mais } \\
\text { informados e comunicativos os } \\
\text { trabalhadores e os usuários, melhor será } \\
\text { a construção do espaço de acolher. }\end{array}$ \\
\hline
\end{tabular}


Principais desafios do acolhimento na prática da atenção à saúde bucal: subsídios iniciais para uma crítica

\begin{tabular}{|c|c|c|c|c|c|c|}
\hline $\begin{array}{l}\text { Silva, Gomes } \\
\text { Filho - } 2012\end{array}$ & $\begin{array}{l}\text { Qualitativa } \\
\text { Descritiva }\end{array}$ & $\begin{array}{l}\text { Não apresenta u } \\
\text { acolhimento. }\end{array}$ & conceito & sobre & $\begin{array}{l}\text { Os discursos dos sujeitos de pesquisa } \\
\text { expressam a satisfação com a } \\
\text { qualidade do atendimento prestado } \\
\text { pela ESB. }\end{array}$ & $\begin{array}{l}\text { Não apresenta desafios relacionados ao } \\
\text { acolhimento. }\end{array}$ \\
\hline $\begin{array}{l}\text { Cavalcanti et al. } \\
-2012\end{array}$ & $\begin{array}{l}\text { Pesquisa- } \\
\text { ação, com } \\
\text { observação } \\
\text { direta } \\
\text { extensiva e } \\
\text { intensiva }\end{array}$ & $\begin{array}{l}\text { Não apresenta u } \\
\text { acolhimento. }\end{array}$ & conceito & sobre & 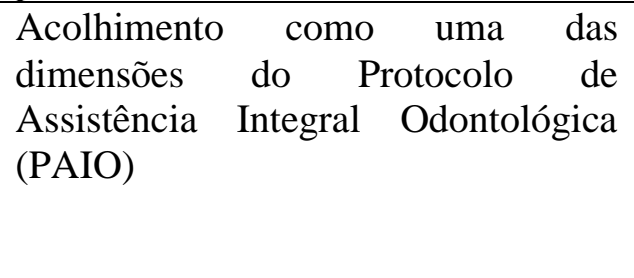 & $\begin{array}{l}\text { Pacientes atendidos pelo protocolo } \\
\text { reconhecem a importância do } \\
\text { acolhimento }(n=5) \text {. }\end{array}$ \\
\hline $\begin{array}{l}\text { Dantas et al. - } \\
2012\end{array}$ & $\begin{array}{l}\text { Relato de } \\
\text { caso }\end{array}$ & $\begin{array}{l}\text { Não apresenta } \mathrm{u} \\
\text { acolhimento. }\end{array}$ & conceito & sobre & $\begin{array}{l}\text { Não apresenta a importância do } \\
\text { acolhimento. }\end{array}$ & $\begin{array}{l}\text { A equipe do setor de recepção pertencer } \\
\text { na maioria das vezes a outras unidades } \\
\text { da Guarnição o que dificulta o } \\
\text { acolhimento. } \\
\text { Dentre as estratégias para a resolução, } \\
\text { a maioria passa pela implantação do } \\
\text { acolhimento inclusive propondo-o } \\
\text { como substituição à triagem. } \\
\text { A ideia básica é limitar o horário e não } \\
\text { o número de pessoas e, pela } \\
\text { implantação do acolhimento, } \\
\text { humanizar o atendimento, respeitando } \\
\text { as necessidades sentidas do usuário, } \\
\text { contrabalançando com a necessidade } \\
\text { real e a capacidade do serviço. }\end{array}$ \\
\hline $\begin{array}{l}\text { Barros, Botazzo - } \\
2011\end{array}$ & $\begin{array}{l}\text { Pesquisa de } \\
\text { intervenção } \\
\text { em atividade } \\
\text { experimental }\end{array}$ & $\begin{array}{l}\text { Não apresenta u } \\
\text { acolhimento. }\end{array}$ & conceito & sobre & $\begin{array}{l}\text { Aponta, apenas que, uma boa } \\
\text { anamnese prescinde de } 05 \text { passos } \\
\text { fundamentais: acolhimento do } \\
\text { usuário e sua queixa; construção da } \\
\text { história da doença/queixa atual; LHC; } \\
\text { interrogatório sobre os diferentes } \\
\text { aparelhos; história alimentar, familiar } \\
\text { e socioeconômica. }\end{array}$ & $\begin{array}{l}\text { Não apresenta desafios relacionados ao } \\
\text { acolhimento. }\end{array}$ \\
\hline
\end{tabular}




\begin{tabular}{|c|c|c|c|c|}
\hline $\begin{array}{l}\text { Szpilman, } \\
\text { Oliveira - } 2011\end{array}$ & Qualitativa & $\begin{array}{l}\text { Acolhimento é o receber bem, o dar } \\
\text { respostas às necessidades de saúde da } \\
\text { população. }\end{array}$ & $\begin{array}{l}\text { Não apresenta a importância do } \\
\text { acolhimento. }\end{array}$ & $\begin{array}{l}\text { Percebe-se na fala dos sujeitos } \\
\text { (usuário) um total desconhecimento do } \\
\text { que é de fato o acolhimento. } \\
\text { Muitas vezes os usuários apresentam } \\
\text { satisfação quanto ao tratamento } \\
\text { relacional, porém insatisfação quanto } \\
\text { ao procedimento realizado9. Neste } \\
\text { estudo, evidencia-se que o } \\
\text { procedimento é limitado, o que foi } \\
\text { demonstrado na avaliação da } \\
\text { resolutividade, enquanto que o aspecto } \\
\text { relacional foi avaliado positivamente } \\
\text { pelo universo pesquisado. }\end{array}$ \\
\hline $\begin{array}{l}\text { Rodrigues et al. - } \\
2010\end{array}$ & Qualitativa & $\begin{array}{l}\text { Consiste em uma ferramenta que permite o } \\
\text { acesso universal aos serviços, tornando-os } \\
\text { humanizados, integrais, com resolubilidade } \\
\text { e qualidade fazendo com que os problemas } \\
\text { de saúde dos usuários se tornem } \\
\text { responsabilidade dos profissionais. } \\
\text { Acolhimento é um arranjo tecnológico que } \\
\text { busca fornecer acesso aos usuários com o } \\
\text { objetivo de escutar todos os pacientes, } \\
\text { resolver os problemas mais simples e/ou } \\
\text { referenciá-los se necessário. } \\
\text { Acolhimento pressupõe que o serviço de } \\
\text { saúde seja organizado de forma usuário- } \\
\text { centrada, garantido por uma equipe } \\
\text { multiprofissional, nos atos de receber, } \\
\text { escutar, orientar, atender, encaminhar e } \\
\text { acompanhar }\end{array}$ & $\begin{array}{l}\text { É importante para operacionalizar a } \\
\text { integralidade na atenção básica. }\end{array}$ & $\begin{array}{l}\text { "Nós temos uma auxiliar administrativa } \\
\text { né? Que é o primeiro contato da } \\
\text { comunidade com a unidade de saúde, elas } \\
\text { fazem o acolhimento do pessoal". } \\
\text { "Bem, a porta de entrada aqui da unidade } \\
\text { é a recepção. Eles fazem a triagem, e são } \\
\text { recepcionados lá. A gente tenta da melhor } \\
\text { maneira fazer um acolhimento fazer sala } \\
\text { de espera, até na pra da uma qualidade no } \\
\text { atendimento, eles não ficarem muito } \\
\text { tempo lá, como tempo ocioso esperando". } \\
\text { "Com relação ao acolhimento, eu acho } \\
\text { que precisa melhorar mais o acolhimento } \\
\text { da recepção, das técnicas [...] Bem } \\
\text { estressadas, então, acabam nâmo tendo } \\
\text { aquele acolhimento como a gente quer" }\end{array}$ \\
\hline $\begin{array}{l}\text { Nuto et al. - } \\
2010\end{array}$ & $\begin{array}{l}\text { Relato de } \\
\text { experiência }\end{array}$ & $\begin{array}{l}\text { Acolhimento como uma ação tecno- } \\
\text { assistencial, em que o usuário é sujeito } \\
\text { ativo no processo de produção de saúde, }\end{array}$ & $\begin{array}{l}\text { Acolhimento na Estratégia de Saúde } \\
\text { da Família, reforça a importância da } \\
\text { mudança no processo de trabalho para }\end{array}$ & $\begin{array}{l}\text { Descreve uma classificação de risco } \\
\text { que, consideramos, não ser um ato de } \\
\text { acolhimento. }\end{array}$ \\
\hline
\end{tabular}




\begin{tabular}{|c|c|c|c|c|}
\hline & & $\begin{array}{l}\text { sendo mediada por parâmetros técnicos, } \\
\text { éticos, humanitários e de solidariedade. } \\
\text { Consiste na abertura dos serviços para a } \\
\text { demanda, facilitando os processos de } \\
\text { trabalho em saúde, de forma a atender a } \\
\text { todos, assumindo o serviço uma postura } \\
\text { capaz de acolher, escutar e pactuar } \\
\text { respostas mais adequadas aos usuários. }\end{array}$ & $\begin{array}{l}\text { a estruturação de um acolhimento } \\
\text { eficaz, em que deve haver } \\
\text { participação e responsabilização por } \\
\text { todos da equipe. }\end{array}$ & \\
\hline $\begin{array}{l}\text { Paula et al. } \\
2009\end{array}$ & Qualitativa & $\begin{array}{l}\text { Não apresenta um conceito sobre } \\
\text { acolhimento. }\end{array}$ & $\begin{array}{l}\text { Não apresenta a importância do } \\
\text { acolhimento. }\end{array}$ & $\begin{array}{l}\text { Não apresenta desafios relacionados ao } \\
\text { acolhimento. }\end{array}$ \\
\hline $\begin{array}{l}\text { Silveira, Stanke } \\
-2008\end{array}$ & Qualitativa & $\begin{array}{l}\text { Não apresenta um conceito sobre } \\
\text { acolhimento. }\end{array}$ & $\begin{array}{l}\text { Não apresenta a importância do } \\
\text { acolhimento. }\end{array}$ & $\begin{array}{l}\text { Não apresenta desafios relacionados ao } \\
\text { acolhimento. }\end{array}$ \\
\hline $\begin{array}{l}\text { Santos et al. - } \\
2007\end{array}$ & Qualitativa & $\begin{array}{l}\text { Compreendendo-o como ações } \\
\text { comunicacionais, atos de receber e ouvir a } \\
\text { população que procura os serviços de } \\
\text { saúde, dando respostas adequadas a cada } \\
\text { demanda em todo o percurso da busca; } \\
\text { desde a recepção e o atendimento } \\
\text { individual ou coletivo, até o } \\
\text { encaminhamento externo, retorno, } \\
\text { remarcação e alta. }\end{array}$ & $\begin{array}{l}\mathrm{O} \text { acolhimento relaciona-se com a } \\
\text { qualidade dos serviços. }\end{array}$ & $\begin{array}{l}\text { Dificuldades enfrentadas pela } \\
\text { população na busca de garantir o acesso } \\
\text { aos serviços de saúde bucal, que ainda } \\
\text { apresenta relações tensas } \\
\text { principalmente, pela baixa } \\
\text { resolubilidade no atendimento às } \\
\text { necessidades demandadas. }\end{array}$ \\
\hline $\begin{array}{l}\text { Santos, Assis - } \\
2006\end{array}$ & Qualitativa & $\begin{array}{l}\text { Pode ser apreendido como ações } \\
\text { comunicacionais, atos de receber e ouvir a } \\
\text { população que procura os serviços de } \\
\text { saúde, dando respostas adequadas a cada } \\
\text { demanda, em todo o percurso da busca } \\
\text { (recepção, clínica, encaminhamento } \\
\text { externo, retorno, remarcação e alta) }\end{array}$ & $\begin{array}{l}\text { O vínculo estreita-se com o } \\
\text { acolhimento, ampliando os laços } \\
\text { relacionais, desenvolvendo afetos e } \\
\text { potencializando o processo } \\
\text { terapêutico entre os usuários, os } \\
\text { trabalhadores de saúde e os gestores } \\
\text { do sistema }\end{array}$ & $\begin{array}{l}\text { Ações individuais e coletivas com } \\
\text { resolubilidade limitada } \\
\text { Uma relação tensa, conflitante }\end{array}$ \\
\hline
\end{tabular}


Dentre os autores que de certa maneira 'apenas tangenciam' o tema, uns não citam o acolhimento em nenhuma parte do texto mas apresenta-o como indexador ${ }^{14}$, outros apenas citam uma única vez ${ }^{15}$ e outros nem sequer citam o termo acolhimento a não ser no título do trabalho ${ }^{16}$. É possível pensar que, nestes estudos há um uso utilitário do termo que, pode ter como finalidade diversos interesses. Aparentemente, nestes artigos supracitados, há uma intencionalidade de justificar a pesquisa como filiada à área da saúde coletiva (por mais que o conteúdo do texto demonstre o contrário).

Em um estudo ${ }^{17}$, apesar do esforço notável em apreender o conceito, o uso do acolhimento em seus parâmetros operacionais desmonta tal acepção. É evidente que, do ponto de vista da experiência relatada não se trata de um acolhimento e sim uma prática de 'triagem administrativa' com foco eminentemente clínico, como identificado nos excertos retirados do artigo: "Desde o início do Acolhimento, todas as terças-feiras, as atividades estão sendo realizadas regularmente..." "Inicialmente, o (a) facilitador (a) explica o objetivo do acolhimento e pactua com os usuários os critérios para definir a ordem de atendimento". "Desta forma, cada pessoa que chega ao Acolhimento deve participar da atividade educativa antes de fazer o exame intra-oral"17.

Alguns estudos, ao tangenciarem o tema, levam em consideração o acolhimento como uma 'dimensão' ou 'variável' a ser analisada em um processo de utilização/acesso aos serviços ${ }^{18}$, como um elemento essencial para o alcance da integralidade $^{19}$ ou ainda para relacionar as dimensões psicossociais do ser humano com as relacionadas à experiência material do corpo biológico $^{20}$.

Em sua maioria os estudos tomam o acolhimento como um construto ou dimensão a ser avaliada em determinado serviço ou protocolo de ação. Dentre os estudos que apresentam uma conceituação de 'acolhimento', há uma variedade bem significativa que, em síntese pode ser resumida como: "o conjunto de atos de inter-relação empática (receber bem, escutar, orientar, atender, dar respostas, encaminhar e acompanhar) que se utiliza de técnicas (em formato de modelos, arranjos ou ferramentas) para melhor executar esses atos empáticos para com o usuário cujo o objetivo é garantir a adequação do serviço à cada demanda (ou modos de procura) do usuário/população mantendo esse conteúdo inter-relacional em todos os ambientes em que o profissional encontra com o usuário garantindolhes resoluções as suas demandas desde as mais simples até seu trânsito/condução pelo sistema (como no caso do acesso a outros serviços)" 17,21-29.

Dos artigos que justificaram a importância do acolhimento, os argumentos repousaram na síntese: "A importância reside na reorganização dos serviços para superar os entraves através de um diálogo positivo, que deve ocupar todos os espaços e implicar todos os membros da equipe na discussão sobre o acolher, na necessidade de capacitação sobre o tema $e$ na operacionalização do acolhimento como ferramenta de gestão. É importante também porque gera eficiência e produtividade, mesmo quando alguns não se engajam a mudar, potencializando o acesso ao serviço e gerando afetos que estreitam os vínculos e ajudam no processo terapêtico." 17,21-31.

Dos artigos que apresentaram os desafios da implantação do acolhimento nas práticas de atenção à saúde bucal, foi possível agrupá-los em seis blocos. O primeiro, e o mais frequente, é aquele que identifica as 'relações tensas, devido às queixas e falta de resolubilidade do serviço e do sistema' como principal desafio a ser enfrentado. As queixas dos usuários como: "Ter atendimento noturno para as pessoas que 
trabalham", e "Demora pra ser atendido, ter que ir muito cedo" ${ }^{30}$, demonstram a insatisfação com o serviço para a classe trabalhadora. Estes usuários têm dificuldade em acessar os serviços e este é um ponto importante em relação ao acolhimento nos serviços. Pensar no acolhimento, sob epistemologias que focam apenas no nível do encontro diádico, microssocial ou interpessoal, apesar de ser uma construção epistêmica importante ${ }^{32}$, valoriza apenas um lado desta tensão (aquela que detém maior acúmulo de poder na interação) e esta construção intelectual não faz sentido para quem realmente necessita. Nesse sentido, a materialidade da vida concreta dos trabalhadores é imperativa e, conforme os discursos acima, que a 'demora', o 'acordar cedo' (para quem o faz todos os dias) e a 'ausência de atendimento fora da hora do trabalho', desafia os serviços a repensar suas percepções sobre que é acolher.

Para quem consegue atendimento, o acolhimento, mesmo quando realizado sob situações adversas, aparece como algo positivo, como uma 'gratidão' por ter recebido atendimento. Como destacado nos discursos do artigo de Rodrigues et al ${ }^{23}$, a ideia de gratidão fica bem evidente: "Não tenho o que reclamar, $o$ atendimento é muito bom. A atendente apresenta muita simpatia, sabe resolver as coisas". "Achei excelente, fui bem recebido. Desde a recepcionista até o atendimento com o aluno". Entretanto, as relações de trabalho tensionadas, conforme descreve, comprometem o 'todo' do processo de acolher, conforme excerto extraído do estudo de Rodrigues et al (2010) 27: "Com relação ao acolhimento, eu acho que precisa melhorar mais o acolhimento da recepção, das técnicas [...] Bem estressadas, então, acabam não tendo aquele acolhimento como a gente quer".

Mesmo em estudos sob uma abordagem quantitativa, as relações tensionadas do acolhimento, desta vez à demanda espontânea, ainda são identificadas como 'realizadas' com taxas de até $64,1 \%$ segundo os usuários. Quando se reduz à instrumentalização gerencial, tais quais os protocolos de 'acolhimento', as equipes relatam que $75,3 \%$ realizam tal tarefa. Esses dados são interessantes para se refletir sobre o local da produção do 'cuidado' e como a identificação dos problemas não deixam de ocorrer, mesmo em proporções minoritárias, sugerindo que a capacidade, tanto de profissionais quanto de usuários, é limitada diante a lógica procedimental e individualista que os serviços de saúde tendem a incutir.

Outro bloco de desafios constituiu-se em 'não saber o que o acolhimento realmente significa, ${ }^{17,21,23,26}$. Nestes artigos foi possível perceber que a equipe profissional e os gestores locais dos serviços ainda têm grandes dificuldades em compreender o que realmente significa o acolhimento. $\mathrm{O}$ discurso de estudantes também deixa transparecer a falta de compreensão do que seja acolhimento em seu sentido ampliado e a fala dos sujeitos (usuário) também corrobora para a incompreensão do que, em suas visões, seja o acolhimento. Esse 'diálogo entre surdos' promove um distanciamento concreto entre 'o quê dizem' e 'o quê fazem' de fato, a ponto dessa disparidade colonizar o imaginário sobre acolhimento dos pesquisadores da saúde bucal coletiva. É possível perceber em um destes estudos, que, aquilo que os pesquisadores chamam de acolhimento, nada mais é do que uma escala de classificação de risco.

Para os que compreendem o acolhimento, conforme as diversas conceituações compiladas neste artigo em parágrafos anteriores, um terceiro bloco de desafios se apresenta. Desta vez, se aposta na 'substituição de processos de trabalho e atividades de gestão da atenção, identificados como não-acolhimento, por atividades 
acolhedoras'. Alguns autores ${ }^{33}$ identificam que o que estavam realizando era uma triagem administrativa e não acolhimento. Em outros ${ }^{27}$ eles reconhecem a diferença entre triagem e acolhimento, no entanto, recaem na ideia de 'espacialidade específica para acolher' que, como já é sabido, demonstra o quanto o conceito é compreendido de múltiplas formas conforme se identifica no discurso. "[Na recepção] Eles fazem a triagem, e são recepcionados lá. A gente tenta da melhor maneira fazer um acolhimento fazer sala de espera, até pra dar uma qualidade no atendimento, eles não ficarem muito tempo lá, com o tempo ocioso esperando".

Outro bloco de desafios na implantação do acolhimento se relaciona com a 'incapacidade da escuta'. Assim, tradicionalmente, os profissionais do serviço não escutam bem seus usuários durante os encontros e quando há essa escuta mais atenta, os usuários tendem a compreender que a ação da escuta foi mais efetiva do que o próprio procedimento. Isso reitera o ideário de que quanto mais informados e comunicativos são os trabalhadores com os usuários, melhor será a construção do espaço de acolher, no entanto é importante relativizar e considerar que a escuta qualificada, acolhedora e terapêutica, é essencial, mas não deve estar desarticulada de uma boa prática clínicocirúrgica.

Retomando esse ponto, o quinto bloco se refere à 'capacidade clínica dos profissionais em atender as excepcionalidades'. Quando os profissionais não têm as competências e habilidades técnicas desenvolvidas para atender casos menos frequentes, como no caso dos pacientes especiais em Odontologia, conforme descrito no estudo de Lawrence et al. ${ }^{24}$, isso é reconhecida como uma falha no acolhimento, reforçando, mais uma vez que, na ótica do usuário, o acolhimento não está restrito apenas as questões subjetivas dos encontros, pois, para quem necessita de atendimento, além de ter atenção, deseja-se resolubilidade clínica.

Um sexto bloco apontou para a necessidade de 'repensar os vínculos empregatícios' como um desafio que impacta no acolhimento. É sabido que profissionais com vínculos empregatícios frágeis, mal remunerados, sobrecarregados e com metas de produtividade baseadas em procedimentos tendem a minimizar a condição de atenção. Essa 'economia da atenção' é responsável pela superficialidade das interações e reprodutibilidade da lógica egóica que abre espaço para substituição das interações humanas por aquelas mediadas por tecnologia. Se por um lado o pensamento biomédico adota a tecnologia como garantia da objetividade requerida para o processo diagnóstico imparcial ${ }^{34}$, a junção desta forma de produzir o encontro com os vínculos empregatícios precários geram a falácia mais insistentemente repetida na produção do pensamento científico em saúde da qual a humanização (e, portanto, o acolhimento) são portadores: "de que é possível um retorno à não-padronização do diagnóstico... ou um neo-artesanato do processo de diagnose" remetendo-se ao conceito de clínica ampliada ${ }^{35}$. Em que pese a intenção mais genuína dos profissionais em realizá-la, sob essas condições de vida e trabalho, é muito difícil pensar que o 'acolher' perdure em suas práticas cotidianas, conforme os resultados dos estudos demonstram.

Mesmo sob os auspícios da crítica tecida ao acolhimento neste estudo, é fundamental reconhecer as limitações que a captura e análise do objeto aqui confeccionada implica. Em primeiro lugar, capturar um objeto de pesquisa através de uma revisão significa 'observar' o objeto sem sua expressão fenomênica. Este fato leva ao revisor a admitir que as escolhas metodológico-interpretativas dos autores revisados foram as mais 'acertadas'.

Em segundo lugar, a metodologia adotada 
por esta revisão (escopo, abrangência, idiomas etc.) demonstra que novas revisões são necessárias para avançar metodologicamente. É essencial apontar que os critérios adotados limitaram um maior alcance do conteúdo publicado o que certamente permitiu que muitos estudos escapassem ao processo de recuperação.

Por fim, mesmo com todas as limitações supracitadas, compreende-se que, com essa revisão foi possível lançar luz ao acolhimento como um tema importante sobre a atenção à saúde bucal que vem sendo reiteradamente discursado como 'o' fundamento das 'práticas exitosas'. Este estudo teve como fortaleza o intuito de descortinar o véu do senso comum que coloniza a discussão do acolhimento na experiência dos serviços para depositar nela uma maior reflexão crítica, ainda que inicial.

\section{CONCLUSÃO}

De acordo com o exposto acima, fica evidente que os desafios a serem enfrentados na implementação do acolhimento nas práticas de atenção em saúde bucal transitam desde as 'relações tensas, devido às queixas e falta de resolubilidade do serviço e do sistema' até a necessidade de se 'repensar os vínculos empregatícios que comprometem as ações do acolhimento'. Na busca pelo acesso aos serviços de saúde bucal, percebe-se que, nesta tensão, o usuário tende a ser o mais prejudicado pois os serviços ainda apresentam baixa resolubilidade no que se refere às necessidades demandadas demonstrando o quanto as práticas de atenção em saúde bucal apresentam problemas na operacionalização do ato de acolher.

A saúde bucal coletiva vem se apropriando do tema 'acolhimento' segundo a discussão encaminhada no âmbito da Saúde Coletiva refém do discurso manifesto pela PNH. A aposta na ação do acolhimento como proposta micropolítica vem no bojo da compreensão mais parcelar da prática sanitária. Vista como setorial e localizada, e, muitas vezes sem conexão com o todo, esta forma de interpretar o fenômeno vem apresentando sinais de esgotamento em virtude dos desafios que não se superam apenas com a práticas de enfrentamento voluntaristas e em nível local.

Assim sendo, se o acolhimento continuar sendo abordado apenas pela reflexão que o ancora na prática da especificidade local, mais uma vez a visão dos processos sociais como um 'todo' se perderá e, com ela, a chance de superar os problemas cuja abordagem mais 'empiricista' não consegue apontar soluções para além da efemeridade.

\section{ABSTRACT \\ Main challenges of user embracement on oral health care practice: initial subsidies for a critical}

This study aimed to review the main challenges faced by the user embracement as a humanization strategy in oral health care in order to understand how collective oral health has appropriated this theme. It was a narrative review, whose object was the user embracement in oral health practices. The Bireme portal was used to perform the search using the terms 'user embracement' and 'oral health'. Articles with abstract, available in full text and Portuguese language were the inclusion criteria. A total of 19 articles were included, of which $68.5 \%$ were indexed in LILACS. Among the challenges to be faced in the implementation of the user embracement, the main one was 'tense relations, due to the complaints and lack of resolubilities of the service and the system'. As for the appropriation of this theme, the bet made is in the understanding of the user embracement as a micropolitical proposal, discharacterizing it as a relation of production inserted in the social whole.

Key-words: Humanization of Assistance. User Embracement. Oral Health. 


\section{REFERÊNCIAS}

1. Behring ER, Boschetti I. Política Social: fundamentos e história. São Paulo, Cortez, 2011.

2. Soares GB, Borges FT, Santos RR, Garbin CAS, Moimaz SAS, Siqueira CEG. Organizações Sociais de Saúde (OSS): Privatização da Gestão de Serviços de Saúde ou Solução Gerencial para o SUS? Rev Gestão \& Saúde. 2016; 7(2):828-50.

3. Bub MBC, Medrano, C, Silva CD, Wink S, Liss P-E, Santos EKA. Noção de cuidado de si mesmo e conceito de autocuidado na enfermagem. Texto \& Contexto Enferm. 2006; 15:152-7.

4. Brasil. Ministério da Saúde (MS). Secretaria de Atenção à Saúde. Núcleo Técnico da Política de Humanização. Humaniza SUS: documento base para gestores e trabalhadores do SUS. 4a Edição. Brasília: MS; 2010a.

5. Brasil. Ministério da Saúde. Secretaria de Atenção à Saúde. Núcleo Técnico da Política Nacional de Humanização. Acolhimento nas práticas de produção de saúde / Ministério da Saúde, Secretaria de Atenção à Saúde, Núcleo Técnico da Política Nacional de Humanização. - 2. ed. 5. reimp. - Brasília: Editora do Ministério da Saúde, 2010b.

6. Bensaïd D. Os irredutíveis: teoremas da resistência para o tempo presente. São Paulo: Boitempo, 2008.

7. Silva CRA, Lunardi Filho WD, Backes DS, Silveira RS, Lunardi VL, Silva APA. Acolhimento como estratégia do programa nacional de humanização. Ciênc Cuid Saúde. 2011;10(1):35-43.

8. Oliveira JDA. Reformas e Reformismo: "Democracia Progressiva" e Políticas sociais (ou "Para uma teoria política da Reforma Sanitária"). Cad Saúde Pública. 1987; 4(3):360-87.

9. Moraes PA, Bertolozzi MR, Hino P.
Percepções sobre necessidades de saúde na Atenção Básica segundo usuários de um serviço de saúde. Rev Esc Enferm USP. 2011;45(1):19-25.

10. Gazabim Simões Ballarin ML, Bruno de Carvalho F, Ferigato SH, Monteiro Smeke de Miranda I, de Carvalho Magaldi C. Centro de atenção psicossocial: convergência entre saúde mental e coletiva. Psicol Estud. 2011; 16(4):603-611.

11. Marinho PML Campos MPA, Rodrigues EOL, Gois CFL, Barreto IDC. Construção e validação de instrumento de avaliação do uso de tecnologias leves em Unidades de Terapia Intensiva. Rev Latinoam Enferm. 2016; 24:e2816.

12. Tanaka MM, Furlan LL, Branco LM, Valerio NI. Adaptação de alunos de medicina em anos iniciais da formação. Rev Bras Educ Méd. 2016; 40(4):663-668.

13. Rother ET. Editorial: Revisão sistemática $X$ revisão narrativa. Acta Paul Enferm. 2007; 20(2):v-vi.

14. de Paula ACF, Ferreira RC, Rodrigues Neto JF, De Paula AMB. Percepção dos usuários do Sistema Único de Saúde de Montes Claros/MG quanto à saúde bucal e ao serviço público odontológico. Arq Odontol. 2009; 45(4):199-205.

15. Silveira JLGC, Stanke R. Condição e representações da saúde bucal entre os semteto do município de Blumenau - Santa Catarina. Ciênc Cogn. 2008; 13(1):2-11.

16. Costa RM, Teixeira LC, Azoubel E, Azevedo FCG. O paciente diabético na clínica odontológica: diretrizes para o acolhimento e atendimento. Rev Bras Ciênc Saúde. 2016; 20(4):333-340.

17. Nuto SAS, Oliveira GC, Andrade JV, Maia MCG. O acolhimento em saúde bucal na estratégia de saúde da família, Fortaleza-CE: um relato de experiência. Rev APS. 
2010;13(4):505-9.

18. Silva ML, Gomes Filho DL. A Percepção dos usuários sobre a incorporação da Equipe de Saúde Bucal no Programa de Saúde da Família. Pesq Bras Odontoped Clin Integr. 2012; 12(3):369-76.

19. Sanchéz HF, Werneck MAF, Amaral JHL Ferreira EF. A integralidade no cotidiano da atenção à saúde bucal: uma revisão de literatura. Trab Educ Saúde. 2015; 13(1):2014.

20. Barros RS, Botazzo C. Subjetividade e clínica na atenção básica. narrativas, histórias de vida e realidade social. Ciênc Saúde Colet. 2011; 16(11):4337-48.

21. Moimaz SAS, Bordin D, Fadel CB, Santos CB, Garbin CAS, Saliba NA. Qualificação do acolhimento nos serviços de saúde bucal. Cad Saúde Colet. 2017; 25(1):1-6.

22. Cassotti E, Gabriel JO. Organização da atenção em saúde bucal na cidade do Rio de Janeiro: resultados do Programa de Melhoria do acesso e Qualidade da atenção básica. Rev APS. 2016; 19(2):245-260.

23. Rodrigues MP, Costa ICC, Medeiros AR, Sette de Souza PH, Medeiros RM, Carneiro SER, et al. Humanização: fragilidades, desafios e fortalezas em uma escola de odontologia. Espaç Saúde. 2015; 16(3):2738.

24. Lawrence H, Souza LP, Gonçalves FL, Saintrain MVL, Vieira APGF Acesso à saúde bucal pública pelo paciente especial: a ótica do cirurgião-dentista. Rev Bras Promoç Saúde. 2014. 27(2):190-7.

25. Neves M, Pretto SM, Ely HC. Percepções de usuários e trabalhadores de saúde sobre a implantação do acolhimento em uma unidade de saúde em Porto Alegre-RS, Brasil. Rev Odontol UNESP. 2013; 42(5): 364-71.

26. Szpilman ARM, Oliveira AE. A percepção de usuários sobre os serviços de odontologia em unidades de saúde de Vila Velha (ES), Brasil. Espaç Saúde. 2011; 12(2):28-37.

27. Rodrigues AAAO, Fonseca GS, Siqueira DVS, Assis MMA, Nascimento MAA. Práticas da equipe de saúde bucal na estratégia de saúde da família e a (des) construção da integralidade em Feira de Santana-BA. Rev APS. 2010; 13(4):476-85.

28. Santos AM, Assis MMA, Oliveira AAAO, Nascimento MAA, Jorge MSB. Linhas de tensões no processo de acolhimento das equipes de saúde bucal do Programa Saúde da Família: o caso de Alagoinhas, Bahia, Brasil. Cad Saúde Pública. 2007; 23(1):7585.

29. Santos AM, Assis MMA. Da fragmentação à integralidade: construindo e (des)construindo a prática de saúde bucal no Programa de Saúde da Família (PSF) de Alagoinhas, BA. Ciênc Saúde Colet. 2006;11(1):53-61.

30. Bordin D, Fadel CB, Moimaz SAS, Garbin CAS, Saliba NAS. Considerações de profissionais e usuários sobre o serviço público odontológico: um aporte para o planejamento em saúde. Rev APS. 2016; 19(2):221-9.

31. Cavalcanti YW, Barbosa AS, Almeida LFD, Padilha WWN. Avaliação de usuários da atenção básica sobre a implantação de Protocolo de Assistência Integral Odontológica. Pesq Bras Odontoped Clin Integr. 2012; 12(3):405-12.

32. Guatarri F, Rolnik S. Micropolítica. Cartografia do Desejo. Petrópolis: Editora Vozes. 2000.

33. Dantas CTFO, Vazquez FL, Guarda ETA, Meneghim MC, Pereira AC. Organização da demanda em unidade de saúde do exército: estudo de caso. Rev Odontol Metod. 2012; 20(39):131-140.

34. Deslandes S. Humanização: revistando o conceito a partir das contribuições da 
sociologia médica. In:

Humanização

dos cuidados em saúde: conceitos, dilemas e práticas. Rio de Janeiro: Editora Fiocruz, 2006. 416p., p. 33-48.

35. Campos GWS, Amaral MA. A clínica ampliada e compartilhada, a gestão democrática e redes de atenção como referenciais teórico-operacionais para a reforma do hospital. Ciênc Saúde Colet. 2007, 12(4):849-59.

Correspondência para:

Leonardo Carnut

e-mail: leonardo.carnut@gmail.com

Rua Alves Guimarães, 642/151

05410-001 Pinheiros, São Paulo/SP 